\title{
Double mitral valve orifice in atrioventricular defects
}

\author{
CAROLE WARNES, JANE SOMERVILLE \\ From the Paediatric and Adolescent Unit, National Heart Hospital and Cardiothoracic Institute, London
}

SUMMARY Eleven patients with double mitral valve orifice and atrioventricular defects were studied, and the diagnosis proven by open heart surgery. The correct preoperative diagnosis was suggested by a characteristic angiographic appearance of the medial border of the left ventricle. M-mode echocardiography may show the two orifices which are better seen on two dimensional echocardiography. Two operative deaths occurred in patients with a slightly obstructive valve, and one late death followed mitral valve replacement. Eight patients did well after minor repair to a cleft, or leaving the valve untouched. Occasionally a double mitral orifice, if disorganised and slightly stenotic, may cause early deterioration in a patient with an otherwise uncomplicated ostium primum defect. The surgeon should be forewarned of this mitral anomaly since simple repair may be difficult.

The mitral valve in all forms of atrioventricular defects is pathologically abnormal, with a characteristic cleft in the anterior cusp which may be partial or complete. In 3 to $5 \%$ of cases, however, a double orifice mitral valve is found. ${ }^{1}$ This valve structure presents an unusual appearance for the surgeon meeting it for the first time. Irrespective of whether the valve is regurgitant or stenotic, even the most experienced surgeon may be faced with a problem when attempting to repair it.

Since this lesion is uncommon, it was considered useful to review our clinical experience in order to establish whether accurate preoperative diagnosis is possible, and to examine the outcome of surgical treatment.

\section{Subjects}

Since 1962, 11 patients were encountered with double orifice mitral valve complicating an atrioventricular defect. The correct anatomical diagnosis were made before surgery in the last five patients in the series, based on earlier experience. All patients had open heart surgery. The clinical data are summarised (Table).

There were eight male and three female patients, aged between 10 months and 20 years. Ten patients had an ostium primum defect and one had a single atrium.

All patients had routine clinical examination, elec-

trocardiogram, and chest radiograph before operation.

Cardiac catheterisation and angiography were subsequently performed and the diagnosis of atrioventricular defect correctly made from the appearances of left ventricular angiography.

M-mode echocardiography was available in five patients. Two dimensional echocardiography was performed recently as part of the routine assessment of all children with congenital heart disease, including the last two patients in the series.

The 11 patients had closure of the ostium primum defect, or partitioning of the single atrium with cardiopulmonary bypass.

The survivors have been followed up for two to 17 years (mean nine years) and all have been examined in the last year.

\section{CLINICAL PRESENTATION}

Eight patients had both recurrent chest infections and mild exertional dyspnoea. One patient aged 12 years was asymptomatic. The two youngest patients, aged 10 months and 3 years, presented in heart failure which responded in part to conventional medication. Both were underweight and the 3 year old had an added supramitral valve membrane causing obstruction above the small double orifice valve beneath it.

A pansystolic murmur of varying intensity was present at the apex and transmitted to the left sternal edge in all patients. One patient had a prominent api$\mathrm{cal}$ mitral diastolic murmur. Other features were the same as those found in conventional ostium primum defects. 
Table Summary of clinical data on 11 patients with double mitral orifice and atrioventricular defects

\begin{tabular}{|c|c|c|c|c|c|c|}
\hline Case No. & Age (y) & $P A P(m m H g)$ & $M R$ grade & Additional lesion & Operation & Result \\
\hline $\begin{array}{r}1 \\
2 \\
3 \\
4 \\
5 \\
6 \\
7 \\
8 \\
9 \\
10 \\
11\end{array}$ & $\begin{array}{l}12 \\
5 \\
6 / 12 \\
3 \\
10 \\
10 / 12 \\
14 \\
2 \\
20 \\
5 \\
4\end{array}$ & $\begin{array}{l}25 / 18 \\
23 / 8 \\
26 / 12 \\
30 / 12 \\
\\
55 / 20 \\
24 / 10 \\
25 / 10 \\
42 / 20 \\
80 / 40 \\
50 / 28\end{array}$ & $\begin{array}{l}1 \\
1 \\
1 \\
1 \\
3 \\
1 \\
3 \\
1 \\
1 \\
2 \\
1 \\
2 \\
1\end{array}$ & $\begin{array}{l}\text { Supravalve MS } \\
\text { Separate secundum ASD } \\
\text { Duct ligated at age } 2\end{array}$ & $\begin{array}{l}\text { Cleft sutured } \\
\text { Cleft sutured } \\
\text { Cleft sutured } \\
\text { Removed, septum divided } \\
\text { Cleft sutured, MVR } \\
\text { Septum divided } \\
\text { Valved untouched } \\
\text { Cleft sutured } \\
\text { Cleft sutured } \\
\text { Valve untouched } \\
\text { Valve untouched }\end{array}$ & $\begin{array}{l}\text { Died } \\
\text { Died } \\
\text { Died }\end{array}$ \\
\hline
\end{tabular}

ASD, atrial septal defect; MR, mitral regurgitation; MS, mitral stenosis; MVR, mitral valve replacement; PAP, pulmonary artery pressure.

The electrocardiograms were available in 10 patients; all had right bundle-branch block and left axis deviation.

\section{ECHOCARDIOGRAPHY}

On the M-mode, the characteristic features of ostium primum defects with a cleft anterior mitral cusp are prolonged diastolic apposition of the anterior leaflet to the interventricular septum and sometimes multiple systolic echoes as the irregular mitral leaflets attempt to close during systole (Fig. 1A). ${ }^{2-4}$

In this series with double orifice mitral valve, the leaflets appeared more thickened and the anterior cusps moved strangely and irregularly with an apparently limited diastolic excursion. These changes, however, only raise the suspicion of double orifice mitral valve and were not diagnostic. In one patient two separate mitral valve orifices, of similar size and at slightly different planes of ultrasound, were seen within the left ventricular cavity (Fig. 1B).

The two dimensional echocardiography in our two patients was useful. In the short axis view the mitral valve was viewed from below. In the presence of the ostium primum cleft mitral valve the diastolic "fishmouth" appearance of a normal valve is replaced by an almost triangular configuration, ${ }^{5}$ with separation of the anterior components of the mitral valve leaflet (Fig. 2A). We noted that the double orifice mitral valve appeared as two separate "holes" in the cusps. These "holes" were the two mitral orifices, approximately the same size, open in diastole (Fig. 2B).

In the long axis view in the same patient, a central bridge of tissue could be seen to divide the two orifices, one of which is angled more towards the interventricular septum, and the other more towards the apex (Fig. 3).

\section{INVASIVE INVESTIGATION}

Left ventriculography in the routine anteroposterior projection shows the medial border of the left ven- tricle to be bound by the abnormal anterior cusp of the mitral valve, ${ }^{6}$ as is characteristic of atrioventricular defects; the narrowing or "gooseneck" deformity was obvious in diastole.

A striking feature in the patients with double orifice mitral valve, however, was the appearance of a double row of crenations on the medial border of the left ventricle (Fig. 4A), with less mobility of the superior part of the valve than is usual for an atrioventricular defect.

In four patients, two separate jets of dye (Fig. 4B) were observed to reflux into the left and right atria. This appearance is not diagnostic of double mitral orifice and may occur with a simple cleft valve but it is suggestive of the diagnosis when associated with a double row of crenations.

\section{SURGICAL TREATMENT}

Eleven patients had repair of the atrioventricular defect. In all, the two orifices were of similar size but the arrangement of the supporting chordae was variable. Most commonly, each valvular apparatus had its own chordae tendineae attached to papillary muscles located at different sites.

In six patients with mild mitral regurgitation, one of the orifices had an associated cleft through which the regurgitation occurred; this was repaired. Five patients with directly sutured clefts did well and only had trivial mitral regurgitation two to 14 years later. One patient, however, operated on elsewhere developed such serious mitral obstruction immediately after repair of the cleft that the mitral valve had to be replaced with a Hancock prosthesis. He died three years later from the effects of a severely calcified obstructed mitral prosthesis and acquired subaortic stenosis. ${ }^{7}$

In three of the remaining five patients, both orifices appeared competent at operation, and the valve was not touched.

In the other two patients, more radical repair of the valve was attempted. In one, the tethered chordae 


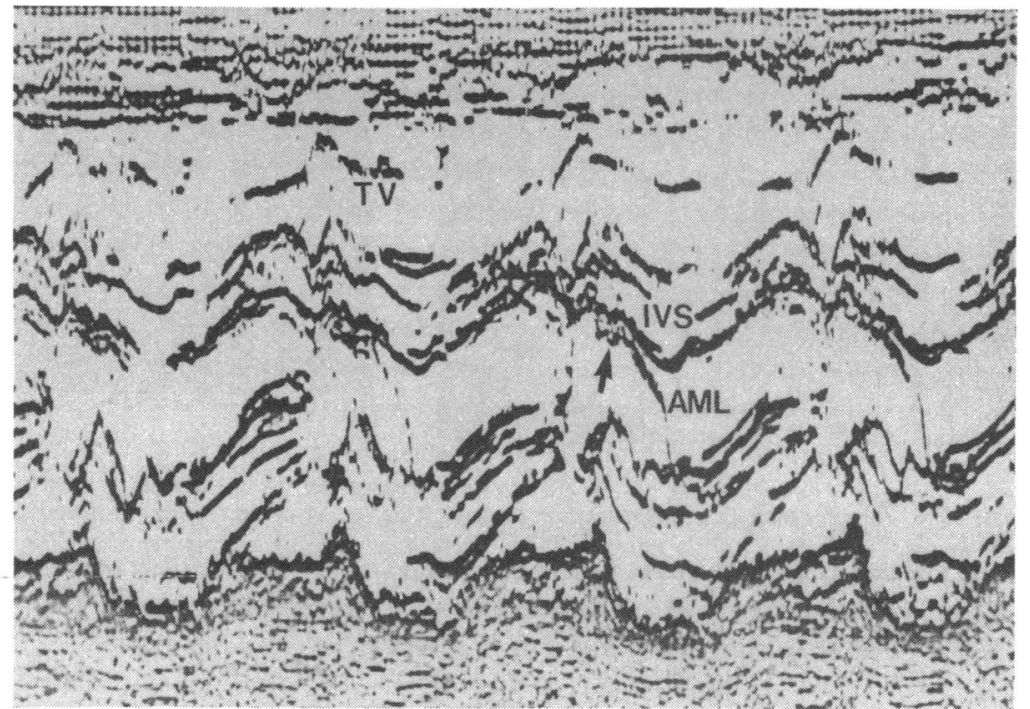

(A)

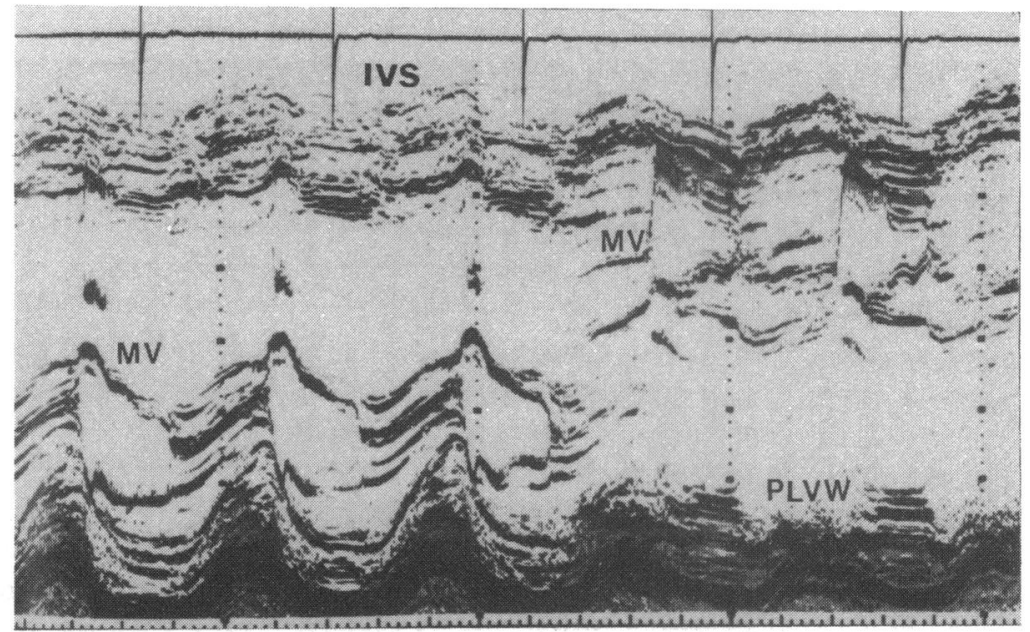

(B)

Fig. 1 (A) Typical M-mode appearance of a cleft mitral valve in an ostium primum defect. Note the prolonged diastolic apposition (arrowed) of the anterior mitral leaflet to the interventricular septum. IVS, interventricular septum; TV, tricuspid valve; $A M L$, anterior mitral valve leaflet. (B) $M$-mode echocardiogram from a patient with a double orifice mitral valve. In the left of the picture one mitral orifice $(M V)$ is seen close to the posterior left ventricular wall (PLVW), and to the right another mitral orifice is seen at a slightly different plane of ultrasound (MV). IVS, interventricular septum. 


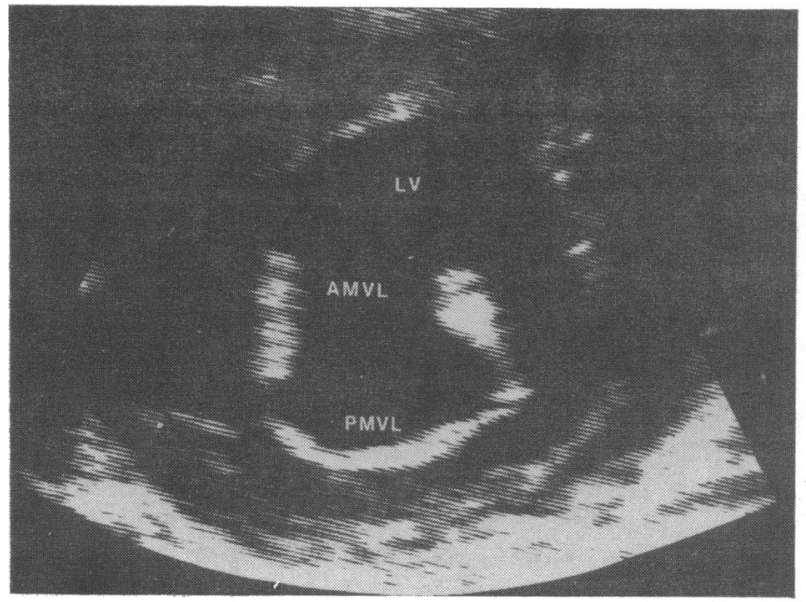

(A)

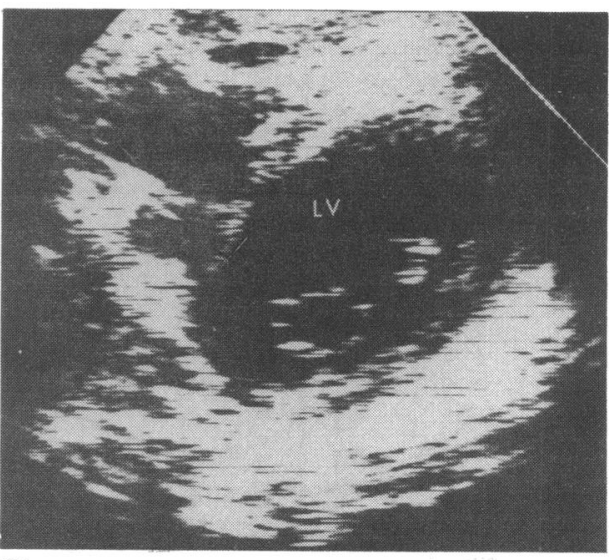

(B)

Fig. 2 (A) Short axis view. Two dimensional echocardiogram showing a cleft anterior cusp of the mitral valve in an ostium primum defect. The normal "fishmouth" appearance of the mitral valve is replaced by a triangular configuration with separation of the components of the anterior mitral leaflet. $L V$, left ventricle; $A M V L$, anterior mitral valve leaflet; $P M V L$, posterior mitral valve leaflet. (B) Short axis view of two dimensional echocardiogram of a double orifice mitral valve (case 10). Two "holes" of similar size are seen within the left ventricular cavity. $L V$, left ventricle.

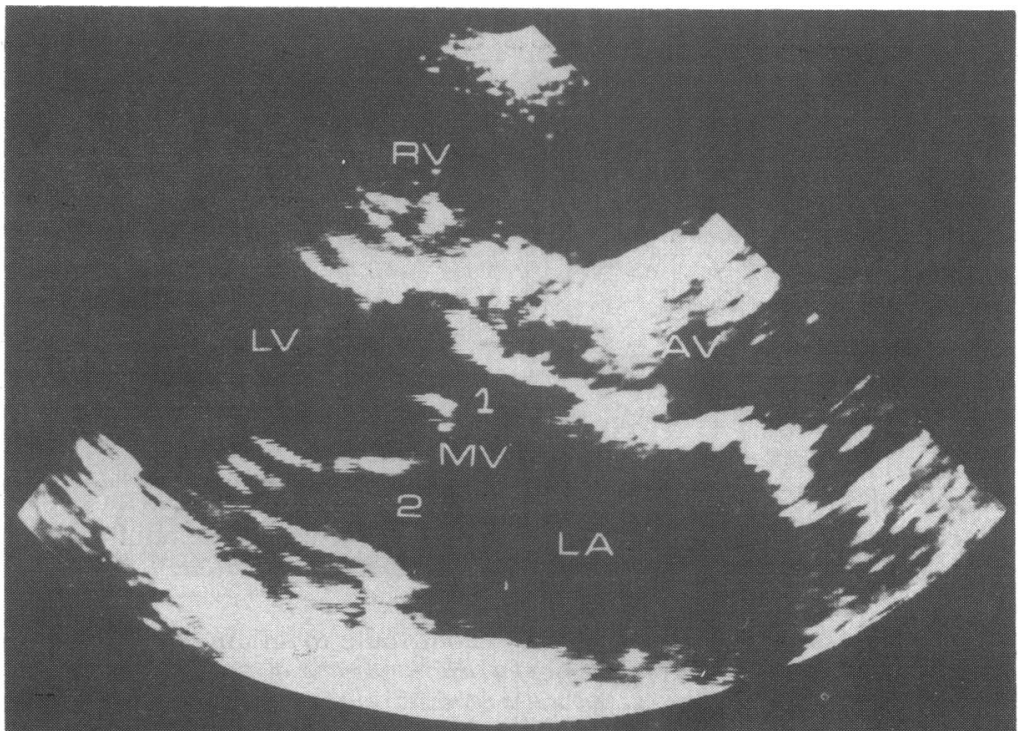

Fig. 3 Long axis view of two dimensional echocardiogram of the same patient (case 10). Two orifices of the mitral valve are seen, one angled towards the interventricular septum $\left(M V\right.$ ) and the other more towards the apex $\left(M V_{2}\right)$. LA, left atrium; $L V$, left ventricle; $R V$, right ventricle; $A V$, aortic valve. 


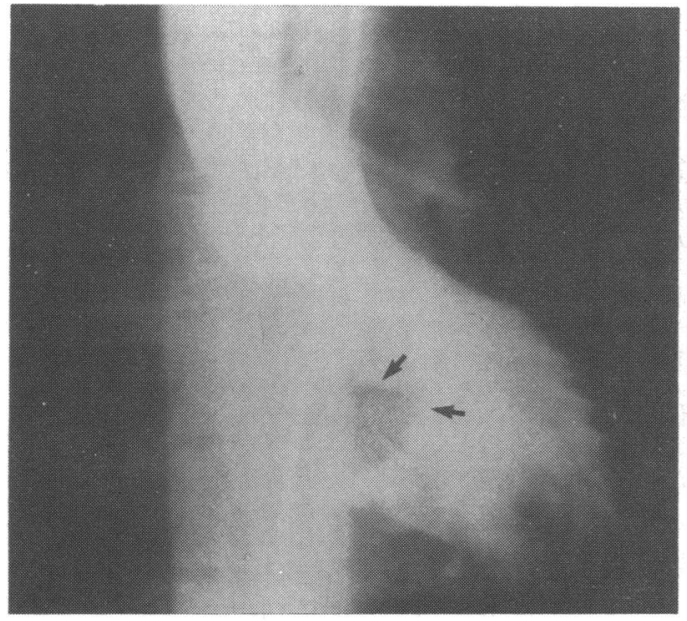

(A)

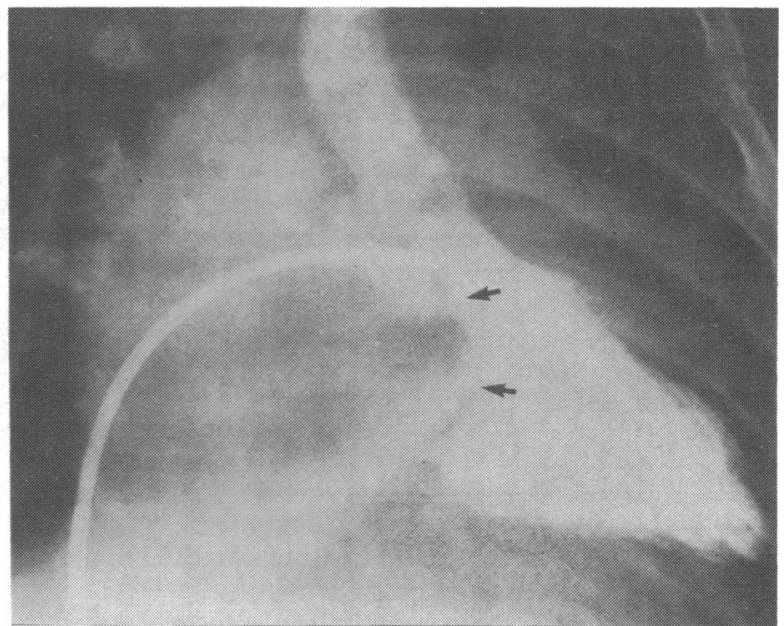

(B)

Fig. 4 (A) Left ventricular angiogram in the anteroposterior view showing the irregular medial border formed by the anterior cusp of the mitral valve in a patient with ostium primum defect and double orifice mitral valve. The arrows show the double row of crenations forming the irregular medial border. (B) Left ventricular angiogram in the same view of a different patient with the same lesion. The arrows show the two separated jets in different directions.

arose from two papillary muscles and additional left atrial obstruction was caused by a supramitral membrane which was excised. The second patient had abnormal chordae tethering the septal leaflet of the mitral valve to the crest of the ventricular septum and thereby limiting its mobility. In both cases the bridge of tissue between the two orifices was divided. This produced regurgitation and a flail segment of the posterior cusp which was reattached to the posterior papillary muscle. The left atrial pressure then rose dramatically and they died in pulmonary oedema.

\section{Late results}

The eight survivors have been followed for two to 17 years (mean nine years) and all have a normal exercise capacity. Two have been recatheterised; both had trivial mitral regurgitation, but the patient with common atrium had residual pulmonary hypertension. The angiographic appearances of the mitral valve were as expected, that is the same as before operation. The other six patients have trivial or no mitral regurgitation and $M$-mode and two dimensional echocardiography show the repaired valves to be mobile, but with increased systolic and diastolic echo density.

Two have required permanent pacemakers since their operation, one for complete heart block 10 years after operation. In the other, a dual demand pacemaker was inserted six years after operation for sinus bradycardia and atrioventricular nodal re-entry tachycardia.

\section{Discussion}

Double orifice mitral valve is a rare anomaly. It may occur as an isolated lesion or exceptionally in association with coarctation of the aorta, persistent ductus arteriosus, and transposition of the great arteries. ${ }^{8-10}$ Recently we have found it on the right side in a patient with atrioventricular discordance (corrected transposition).

More commonly, it occurs with any form of atrioventricular defect and in our experience has been seen in $3 \%$ of ostium primum defects and $1 \%$ of patients with common atrium. None in this series had a complete atrioventricular canal though the association has been documented. ${ }^{1112}$

Wakai and Edwards ${ }^{12}$ reported that double mitral orifice occurred in $10 \%$ of postmortem specimens of atrioventricular defects. The majority of patients in their series were infants below $2 \frac{1}{2}$ years. This may explain the higher incidence of the anomaly than in the current series which mostly includes older children, adolescents, and adults. If this is the true explanation, it suggests that double orifice mitral valve may be a bad associated lesion in atrioventricular canal and contribute to an unfavourable prognosis.

Two of the 10 patients with ostium primum defect were seriously disabled in the first two years of life. This is unusual in ostium primum defects unless there is an additional lesion or torrential mitral regurgitation, and suggests that there was left atrial obstruction, obviously contributed to in one patient by the 
added supramitral membrane. Thus, double orifice mitral valve should be suspected in any disabled infant with an ostium primum defect and functionally intact ventricular septum.

There are no unusual clinical signs to suggest double orifice mitral valve and the electrocardiogram and chest $x$-ray film show no special features. M-mode echocardiography may be suggestive when it shows unusual thickening of the anterior mitral cusps. This is possibly because there are multiple crenations causing overlap of folds of cusp tissue in the echo planes. In older patients, the anterior cusp may be thicker than usual. The appearance of two separate orifices at different planes of ultrasound is diagnostic and is best seen on two dimensional echocardiography where the separate valve orifices point in different directions. The cusps do not move normally or fully.

Left ventricular angiograms in the anteroposterior view showed a double row of crenations. This gave the impression of a very irregular medial border, and when associated with two separate jets in systole and a smooth edge moving little in diastole, was highly suggestive of double mitral orifice. The finding of two separate systolic jets was not diagnostic, as this sign was seen with simple cleft and multiple short chordae. The appearances of fine and multiple "double track" crenations, however, relate to the wrinkles around the orifices not being exactly but nearly in the same plane and there are more chordae and tethering than is usual in a simple cleft where only the anterior cusp is bound down.

The haemodynamic effects of a double mitral valve orifice are variable, ranging from virtual competence to gross regurgitation, particularly when the cleft extended from one orifice. Alternatively, the orifices can be small with tethered chordal attachments causing mitral obstruction. Added bacterial endocarditis may cause cusp destruction.

We believe this mitral anomaly can be difficult for even the most experienced surgeon to assess. The function must be carefully tested to establish the exact cause of any regurgitation. The best surgical results are obtained when the valve is sufficiently competent to be left untouched. When the regurgitation is caused by a cleft in one orifice, minor repair of the cleft may well result in satisfactory function. Radical repair of a double orifice mitral valve, however, with division of the central bridge of tissue, described by Reed et al., ${ }^{13}$ when combined with reattachment of the papillary muscles in an attempt to construct a single competent orifice was disastrous in this series. Thus, limited surgical repair, if possible is to be recommended.

The authors acknowledge the help of Dr M Ballester with the echocardiography and the surgeons, $\mathrm{Mr} \mathrm{D}$ Ross, Mr K Ross, and Mr M Yacoub.

\section{References}

1 Somerville J. Atrioventricular defects. London: MD Thesis, 1966.

2 Williams RG, Rudd M. Echocardiographic features of endocardial cushion defects. Circulation 1974; 49: 41822.

3 Pieroni DR, Homcy E, Freedom RM. Echocardiography in atrioventricular canal defect: a clinical spectrum. $A m \mathcal{F}$ Cardiol 1975; 35: 54-8.

4 Bass JL, Bessinger FB Jr, Lawrence C. Echocardiographic differentiation of partial and complete atrioventricular canal. Circulation 1978; 57: 1144-50.

5 Hagler DJ, Tajik AJ, Seward JB, Mair DD, Ritter DG. Real-time wide-angle sector echocardiography: atrioventricular canal defects. Circulation 1979; 59: 140-50.

6 Baron MG, Wolf BS, Steinfeld L, Van Mierop LHS. Endocardial cushion defects-specific diagnosis by angiocardiography. Am $\mathcal{f}$ Cardiol 1964; 13: 162-75.

7 Taylor NC, Somerville J. Fixed subaortic stenosis after repair of ostium primum defects. $\mathrm{Br}$ Heart $\mathcal{F}$ 1981; 45: 689-97.

8 Wimsatt WA, Lewis FT. Duplication of the mitral valve and a rare apical interventricular foramen in the heart of a yak calf. Am $\mathcal{f}$ Anat 1948; 83: 67-107.

9 Schraft WC Jr, Lisa JR. Duplication of the mitral valve. Case report and review of the literature. Am Heart $\mathcal{F}$ 1950; 39: 136-40.

10 Wigle ED. Duplication of the mitral valve. $\mathrm{Br} \mathrm{Heart} \mathcal{f}$ 1957; 19: 296-300.

11 Mehrizi A, Hutchins GM, Rowe RD. Double orifice of the mitral valve. Bull fohns Hopkins Hosp 1965; 177: 8-15.

12 Wakai CS, Edwards JE. Pathologic study of persistent common atrioventricular canal. Am Heart $\mathcal{f}$ 1958; 56: 779-94.

13 Reed GE, Cortes LE, Clauss RH, Reppert EH. The surgical repair of duplication of the mitral orifice. Ann Thorac Surg 1970; 9: 81-5.

Requests for reprints to Dr Jane Somerville, Paediatric \& Adolescent Unit, National Heart Hospital, Westmoreland Street, London W1M 8BA. 